\title{
GLACIOLOGICAL INVESTIGATIONS USING THE SYNTHETIC APERTURE RADAR IMAGING SYSTEM
}

by

\author{
R.A. Bindschadler
}

(NASA/Goddard Space Flight Center, Greenbelt, MD 20771, U.S.A.)

K.C. Jezek

(Thayer School, Dartmouth College and CRREL, Hanover, NH 03755, U.S.A.)

and

J. Crawford

(Jet Propulsion Laboratory, Pasadena, CA 91103, U.S.A.)

\begin{abstract}
Numerous examples of synthetic aperture radar (SAR) imagery of ice sheets are shown and prominent features of glaciological importance which appear in the images are discussed. Features which can be identified include surface undulations, ice-flow lines, crevasses, icebergs, lakes, and streams (even lakes and streams which are inactive or covered by snow), and possibly, the extent of the ablation and wet snow zones. SAR images presented here include both L-band data from the Seasat satellite and X-band data from an airborne radar. These two data sets overlap at a part of eastern Greenland where a direct comparison can be made between two images. Comparison is also made between SAR and Landsat images in western Greenland. It is concluded that SAR and Landsat are highly complementary instruments; Landsat images contain minimal distortion while SAR's all-weather, day/night capability plus its ability to penetrate snow provide glaciologists with an additional and very powerful tool for research.
\end{abstract}

\section{INTRODUCTION}

The importance of ice sheets in the global climate system is becoming increasingly apparent, yet they remain the least explored and most poorly understood regions of the Earth. Vast size, remoteness, and inhospitable conditions have limited scientific investigations on the surface of the polar ice sheets, while frequent cloud cover and the extended polar night severely restrict visible observations from aircraft or from space. Before their role in global climate can be assessed, techniques must be developed which permit us to study repeatedly the entirety of these ice sheets on time-scales characteristic of the processes which drive them. Until we accomplish this, we will not be in a position to describe the present behavior of the ice sheets and, more importantly, what the likely future response will be to changing climate.

In this paper we discuss the utility of synthetic aperture radar (SAR) in studying ice sheets. SAR is an active microwave system with the commensurate benefits of high-resolution and all-weather/day-night capability. Although it has generally been held that the potential for successfully exploiting SAR data in glaciology is high (Rott and others 1985; Thomas and others 1985), there are very few data to support this contention. The data we present here significantly expand the types of ice-sheet surfaces imaged with SAR and illustrate that a SAR image of any region of the ice sheet is rich with glaciologically significant information. The images we present reveal surface relief on the glacier, the location of calving activity, and surface crevasses. Flow lines in outlet glaciers are easily detected and the data distinctly show surface lakes and streams (both active and relic). Some of our interpretations must remain conjectural; we present corroborative evidence wherever possible. We suggest that SAR imagery can be applied successfully to studies such as: providing measurements of the spatial extent of the ice sheet and ice shelves; identification of present and past flow features; location and configuration of ice rises; and the location of blue-ice zones for meteorite collection.

\section{SYNTHETIC APERTURE RADAR OPERATION}

Synthetic aperture radar (SAR) is a side-looking imaging sensor which transmits coherent electromagnetic pulses towards the Earth's surface and records the backscattered energy. SAR instruments presently being used for remote-sensing applications are typically designed to operate in either the $\mathrm{X}-, \mathrm{C}-$, or L-bands of the microwave part of the spectrum. The major advantage of operating the radar at microwave frequencies is the inherent insensitivity of the signal to clouds or fog. Because SAR is an active device providing its own illumination of the surface, it can be operated at night as well as during the day.

The utility of SAR over real-aperture radars is the capability to achieve high resolution without a large antenna. Cross-track resolution is obtained by using a short pulse or by using a chirp and matched filters. However, unlike conventional radars, along-track resolution is obtained by using the shift in doppler frequency generated by the motion of the antenna relative to the target. The radar compiles amplitude and phase information over the length of the synthetic aperture by successively illuminating the Earth's surface. By processing the histories of amplitude and phase for a target, SAR can obtain a resolution much finer than achieved by conventional radar (Ulaby and others 1982). More importantly, when data are processed in this manner, resolution is independent of range, which makes it ideally suited for space applications.

Intensity variations observed in SAR images are caused by differing amounts of energy scattered back to the instrument. Factors which affect the back-scattered signal include the electrical properties of the material, the surface roughness, and volume inhomogeneities. All of these factors are frequency-dependent. Instrument parameters such as antenna depression angle, and polarization of the transmitted and received signals, also affect the received intensity. 
SYNTHETIC APERTURE RADAR DATA OF ICE SHEETS

The Seasat satellite, launched in June 1978, provided a very limited amount of SAR data of ice sheets including one pass each in eastern and western Greenland, and two passes containing the ice cap Vatnajökull in Iceland (Fig.1). Since that mission, only a few images from the Shuttle

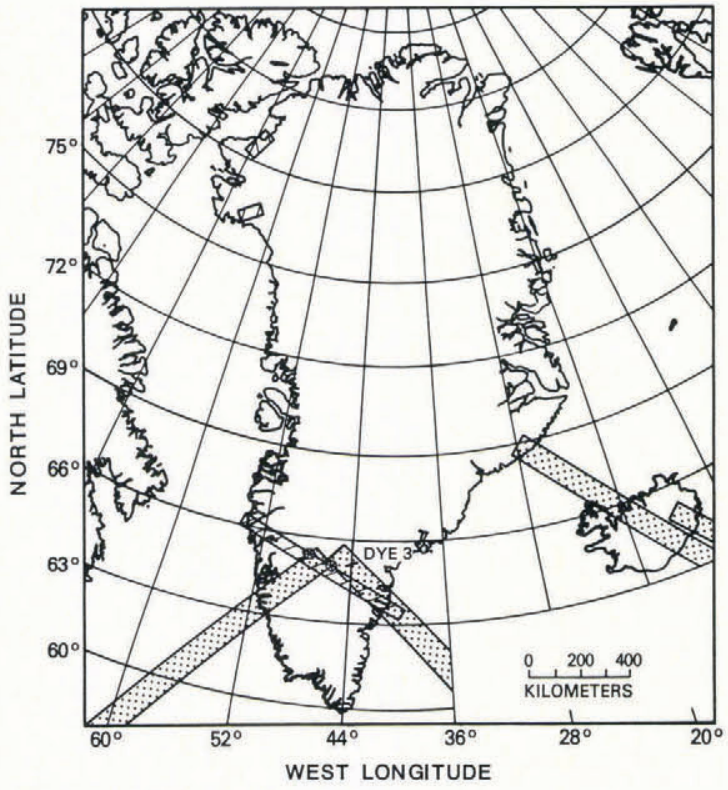

Fig.1. Location map of SAR data in Greenland. Airborne data (cross-hatched strips) are located in two short blocks in northern Greenland as well as a full transect in the south. Seasat data (stippled strips) consist of two swaths in southern Greenland. SAR data in the south overlap surface-strain networks represented in the figure by two spoked wheels and a stake line near station Dye-3.

Imaging Radar-A (SIR-A) containing isolated mountain glaciers have been added to the collection of SAR imagery from space. Seasat SAR operated at $1.275 \mathrm{GHz}(23.5 \mathrm{~cm})$, $\mathrm{HH}$ polarization, with a $25 \mathrm{~m} \times 25 \mathrm{~m}$ ground resolution, a swath width of $100 \mathrm{~km}$, and an antenna depression angle of $67^{\circ}$ (Fu and Holt 1982). Thus, the nominal incidence angle in the center of the swath on horizontal ground was $23^{\circ}$.
Across the swath the incidence angle varied by $\pm 3^{\circ}$ with a lower incidence angle in the near range and larger incidence angle in the far range.

Airborne missions have added significantly to the data base of SAR images of ice. Most recently, a pair of missions dedicated to the collection of SAR data of ice was flown in Greenland including a full transect of the ice sheet (see Fig.1). The airborne data were collected with the STAR-1 system operated by Intera Corporation. This $\mathrm{X}$-band radar operated at $9.4 \mathrm{GHz}(3.2 \mathrm{~cm}), \mathrm{HH}$ polarization, with a ground resolution of $12 \mathrm{~m}$ cross-track and $6 \mathrm{~m}$ along-track (Nichols and others 1986). The swath width was $45 \mathrm{~km}$ with a nominal antenna depression angle of $14^{\circ}$ for an incidence angle of $76^{\circ}$ on a horizontal surface. The range of incidence angles (again, referenced to a horizontal surface) varied by $\pm 3^{\circ}$.

\section{SAR IMAGES FROM SPACE}

Fig.2 is one of the two Seasat SAR images of Greenland. These data were collected over western Greenland and optically processed to produce four film strips (see Fu and Holt 1982). Using maps of the Greenland coast published by the Greenland Geological Survey, it is easy to identify features of the coastline and confirm that the open ocean, coastal mountains, and ice sheet all have distinctive signatures. Concentrating in this paper on the ice sheet, there is a wide variety of glaciologically interesting features revealed in the SAR image. (The ice sheet in Fig.2 is shown in more detail in Fig.7a.) The lower outlet glaciers are marked by areas of intense crevassing as well as lineations running along the flow direction of the glaciers. These lineations are probably medial moraines or surface ridges and troughs. Up-stream, broader lineations mark the flow directions of the ice which feeds the glaciers. These features could be caused by a number of effects: longitudinal stretching of features as they accelerate down-flow, a less-pronounced ridge-trough system, drainage of water in the firn, or a combination of these effects. More obvious water-related features are the smaller, rounder bright spots and the serpentine lines which connect many of them. These features are quite likely surface lakes and stream channels between them. Large drainage streams many meters across have been observed in Greenland. Such a feature, even though narrower than the pixel resolution, would still be discernible due to their continuous nature, just as bridges and roads smaller than the resolution size can be seen on photographs from space. Their brightness

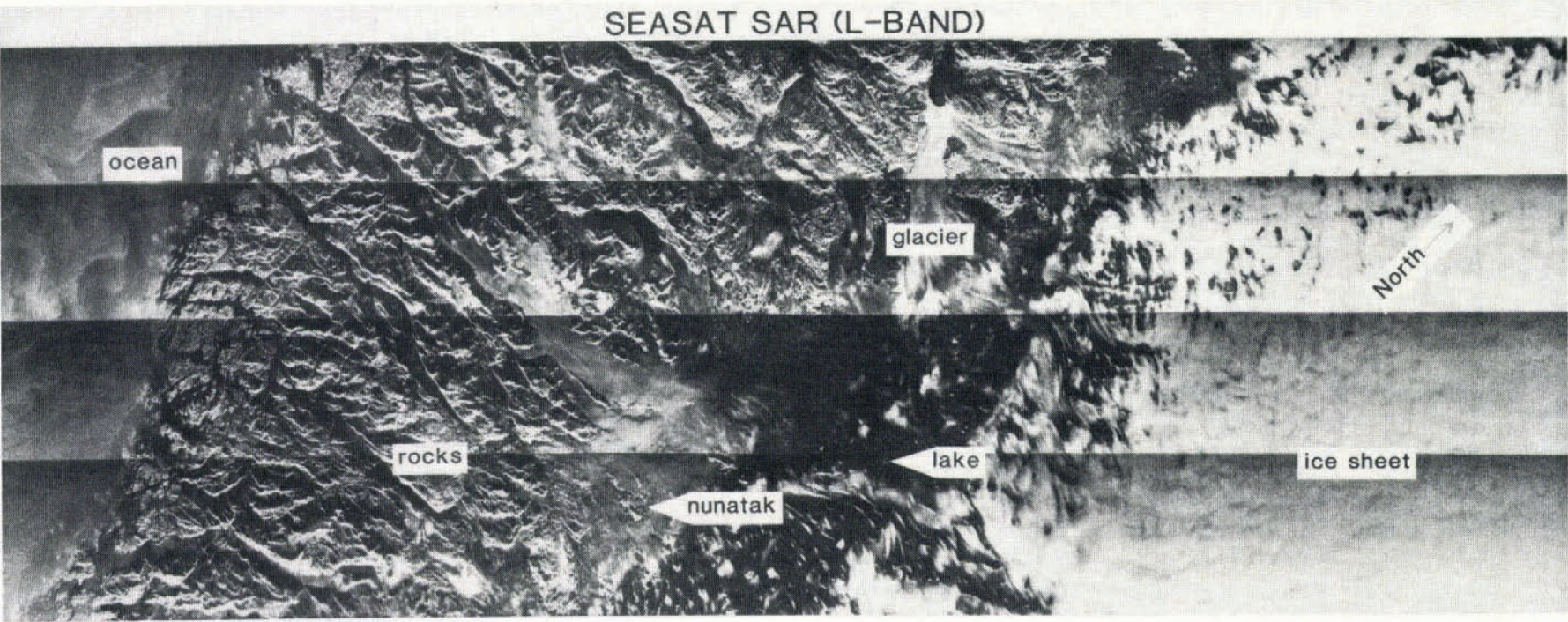

Fig.2 Optically processed Seasat SAR data of western Greenland collected on 9 October 1978. Width of swath is approximately $100 \mathrm{~km}$. Illumination is from the bottom of the figure. Features are discussed in the text. 
probably comes from the fact that the sides of the channels have facets which are oriented so as to provide a good reflection of the radar beam. This effect also causes the crevasse fields to show up as bright areas on the image. An observation which supports this explanation is that most of the crevasse fields and stream channels in Fig. 2 are oriented normal to the illumination direction.

The ice sheet in Fig.2 also shows tonal variability on a broader scale. The darkest region lies just up-stream of the separate outlet glaciers and most likely corresponds to the ablation area of the ice sheet. Gudmandsen (personal communication) has confirmed that the equilibrium line in this region corresponds roughly to the boundary between the dark and light regions of the ice sheet. This interpretation is further supported by the presence of the surface lakes at the up-flow boundary of the darker region. We suggest that the reason this area is dark is that the bare ice or smooth ice surface of the ablation zone acts as a specular reflector for the incident energy. Unless a specularly reflecting surface is inclined normal to the incident beam, less energy from this surface is scattered back to the receiver as compared with the received energy from a more diffuse reflector such as the firn. This discrimination between specular and diffuse-reflecting surfaces is possible even if they are buried, as long as attenuation in the overlying medium is small. Smith and Evans (1972) have shown that L-band radar will have some capability of penetrating dry snow many tens of meters thick. Another alternative explanation of the dark area is that the dark area is wetter and, thus, more radar-absorptive. We feel this explanation is less likely because significant melting is known to occur at elevations above the equilibrium line (i.e. in the brighter area).

Gray patches within this dark region could be caused by a number of effects: residual snow (or deeper snow if the entire area has received recent snow); surfaces inclined more toward the receiver; rougher surfaces; or surfaces with more debris. It is clear that surface measurements simultaneous with SAR imagery are the only indisputable means of determining the proper interpretation of the tonal differences.

Further up-stream, the regional tone switches to a band of dark patches scattered on a light field. This band is approximately $25 \mathrm{~km}$ wide. The spatial scale of the gray patches is similar to the spatial scale of surface undulations as revealed on Landsat imagery, yet we feel it is unlikely that we are measuring topographic variations because the band does not extend to higher elevations while the undulations do continue. It is more likely that the tonal variations are affected by and possibly even controlled by topography. A wind crust might likely form on the windward side of undulations while the leeward side would contain less-consolidated drift. Another possibility is that enhanced melting occurs on south-facing slopes relative to north-facing slopes due to the extra solar radiation. This extra solar input would cause more surface melt and form both a smoother surface and more sub-surface ice lenses both of which would lead to a more specularly reflective target for the SAR. The observation that the gray patches diminish in both size and number in the higher elevations suggests that the cause of the gray patches is related to melt rather than wind. We feel this band corresponds to the slush zone characterized by Benson (personal communication) wherein the snow is saturated at the end of the melt season. The cause of this textural pattern could be due to drier snow with any resident water having been refrozen since the end of the melt season being the bright background, areas of wetter snow being gray, and areas of soaked snow or slush being darkest. Such a band has been observed at numerous places on the ice sheet. The dark streaks are interpreted as being drainage channels of excess water. Because the surface is snow or firn, these dark streaks would comprise slush and have diffuse edges rather than sharp boundaries incised into bare ice.

Furthest inland in Fig.2 the tonal variations are extremely slight. At these elevations, the effects of water and bare or smooth ice have probably diminished, leaving surface topography and volume inhomogeneities as the only causes of spatial variations of radar back-scatter.

The issue of sub-surface penetration is an important one which must be considered very carefully. Rott and others (1985) have shown that penetration depth of dry snow varies with frequency; the lower frequencies (e.g. L-band) penetrating further than higher frequencies (e.g. X-band). Also, Stiles and Ulaby (1982) have determined that penetration depth decreases with liquid water content. In these dependencies, we see a potential for being able to discriminate between surface (e.g. topographic) effects on back-scatter and sub-surface (e.g. ice lenses) effects in dry snow or between dry and wet snow by using multiple frequencies. This will allow the accurate determination of the boundary between the dry-snow zone and the percolation zone as well as the boundary between the percolation zone and the soaked (or wet-snow) zone. These boundaries are important in assessing the mass-balance situation on the ice sheet as well as mapping seasonal snow cover (Rott and others 1985). What is needed to evaluate the potential of this technique for ice-sheet studies is simultaneous SAR imagery of the same areas containing these different zones. Rott and Domik (1984) have used different SAR frequencies in a study area in the Ötztaler Alps in Austria but there is no percolation or dry-snow zone there. We have collected airborne SAR data at X-band which overlap the L-band Seasat SAR data in East Greenland but the airborne data were collected in April 1986 and the Seasat data in September 1978. The comparison of these data will be presented following the discussion of the airborne data alone.
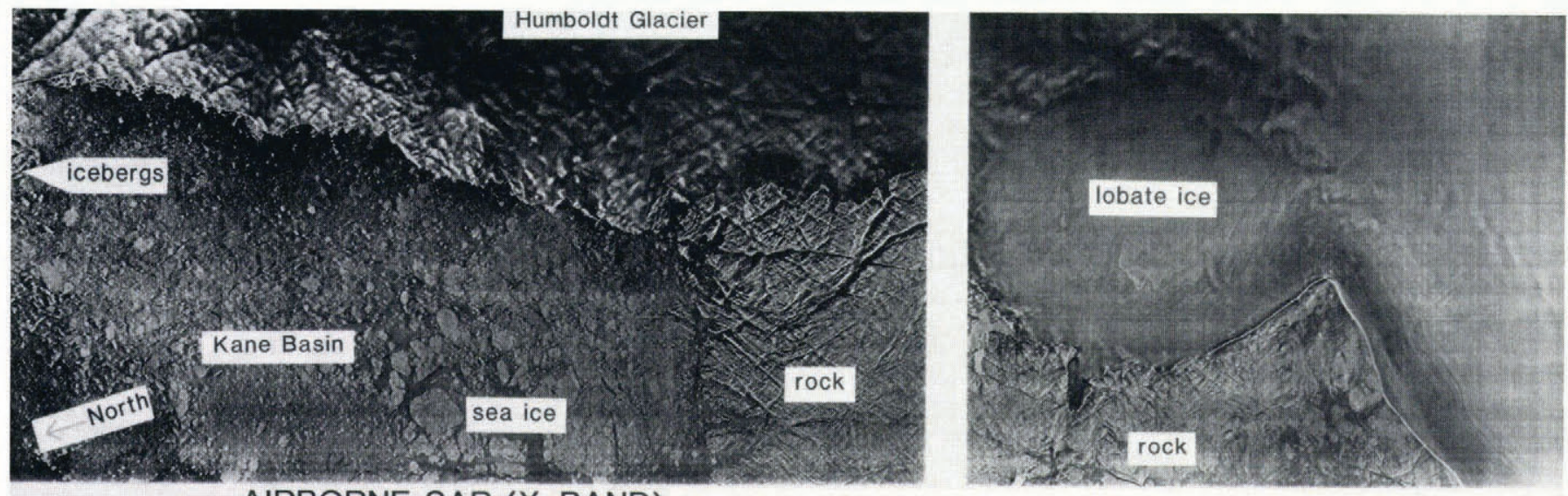

AIRBORNE SAR (X-BAND)

Fig.3. Airborne SAR data of the Humboldt glacier area in north-west Greenland collected on 14 March 1986. Width of swath is approximately $45 \mathrm{~km}$. Illumination is from the bottom of the figure. White band represents interval when no data were collected. 


\section{AIRBORNE SAR IMAGE OF HUMBOLDT GLACIER}

On 14 March 1986, SAR data of the Greenland ice sheet were collected by an aircraft using the STAR-1 SAR system described earlier (see Fig.1). Fig.3 is a part of these data showing the lower section of Humboldt glacier in north-western Greenland. The data are taken at X-band and have a nominal surface resolution of $10 \mathrm{~m}$. The image reveals numerous tabular (longest about $1.6 \mathrm{~km}$ ) and pinnacled icebergs frozen in between floes of sea ice in the Kane Basin. The concentration of icebergs adjacent to the regions of heavy crevassing in the glacier suggests that the calving process primarily occurs within the bright arcuate parts of the glacier. Heavy surface crevassing is observable in these areas and, based on the brighter surface there and the orientation of the SAR, the surface is probably steeper. Ice velocities in this steeper region are probably higher, a necessary condition to replenish the ice lost by calving. Most icebergs have apparently been swept northward along the coast away from the calving centers.

The interior of the glacier has a dark, mottled appearance. This is probably an indication of relief associated with glacier flow over complex basal topography. This assumption is based upon the similar texture between the surface morphology of the exposed bedrock on the flanks of the glacier and the light/dark patterns seen on the glacier. Moreover, melt-water ponds on the surface of the glacier are visible as are melt-water channels directed away from the ponds. We do not mean to suggest that we believe these ponds and channels are active, i.e. filled with water, in March; rather, we believe that they have a different topographic character than the surrounding ice and it is the SAR's sensitivity to this difference which provides evidence for their presence. Notice that a row of melt-water ponds is aligned along a dark linear feature that stretches across most of the image. We suggest that the lineament is a surface depression associated with basal topography.

The mottled appearance characteristic of the Humbold glacier image changes markedly for the lobate ice adjacent to the glacier. The ice in this region terminates on land and the edge of the ice is very clearly marked by a bright line, probably caused by a very steep terminal face. The surface characteristic of this ice is more uniform. Grounded on rock, this ice is probably thicker and less active than Humboldt glacier and, thus, the roughness of the basal topography is not seen in the surface topography. This smooth surface is crossed by a large number of very thin lines which strike normal to the ice margin. This orientation strongly suggests these represent melt-water rivulets, much smaller than the large channels that drain the ponds seen on Humboldt glacier, but far more numerous. They collect only local surface melt-water as they form and run along the fall line of the ice surface. Ponds do not form on this smoother ice but, rather, an intricate, filamentary structure is revealed. In the southernmost ice (far right of Fig.3), the banding parallels the ice edge, while in the lobate ice the banding shows some additional convolution. This convolution resembles morainal features generated in zones of non-uniform ice flow. We suspuct the formation mechanism for these features is similar and that the bands themselves are due to depositional or structural non-conformities within the ice.

AIRBORNE SAR IMAGERY OF CENTRAL GREENLAND

On 14 April 1986, the same instrument collected $\mathrm{X}$-band SAR data on a single transect across the entire Greenland ice sheet. The flight path overlapped areas imaged by the Seasat SAR as well as areas studied by surface parties as part of the Southern Greenland Ice Sheet Program (Whillans and others 1984; Jezek and others 1985) (see Fig.1). A broad tonal patchwork pattern dominates the western margin of the ice sheet shown in Fig.4. We suggest that much of this pattern is correlated with basal topography given the general north-east strike of many of the linear features apparent in the image. This trend is seen in the exposed mountains in the left of Fig. 4 and has been associated with regional, transcurrent faults (Watterson 1978).

Other features which appear in Fig. 4 are the numerous lakes. Fig.5 compares a part of Fig.4 with an aerial photograph of surface lakes in Greenland taken in the summer of 1985 and kindly provided by H. Brecher. The lakes in the photograph are on the order of $500 \mathrm{~m}$ in diameter (personal communication from $\mathrm{H}$. Brecher) and occur at the boundary between bare ice and firn. The photograph was taken further north than Fig.4: in the drainage basin of Jakobshavns glacier, where less surface melting occurs, so it is not surprising that the average size of the lakes is smaller than in the SAR image, but the pattern and shapes of the lakes in the two regions are strikingly similar.

The lakes just right of center in Fig. 4 appear to have a smoother unmodified surface than the lakes further to the right. The texture of these two classes suggests that the smoother surface is a result of an undisturbed and possibly thicker ice cover, while the rougher surface may have been fractured and/or collapsed at the end of the previous melt season. Still other lakes are barely visible, perhaps having been inactive for more than 1 year. These would now be buried beneath accumulated snow but would still be evidenced by the smoother surface as compared with the surrounding undulating topography. The conjecture that buried lakes may be observable is not implausible given the capability of L-band radar to penetrate dry snow. In

\section{AIRBORNE SAR (X-BAND)}

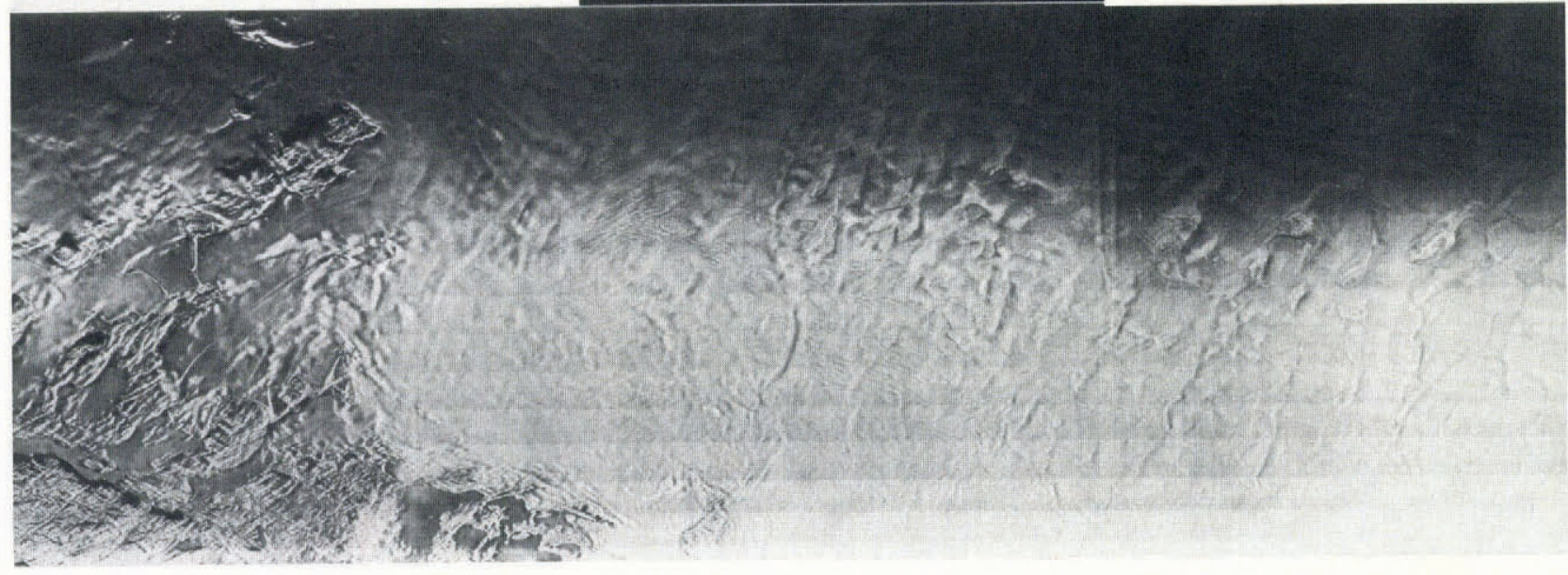

Fig. 4. Western end of airborne SAR data in southern Greenland collected on 14 April 1986. Width of swath is approximately $45 \mathrm{~km}$. Illumination is from the bottom. Antenna depression angle was $14^{\circ}$ over the left two-thirds of the image but was increased to $15^{\circ}$ over the remaining one-third of the image. 

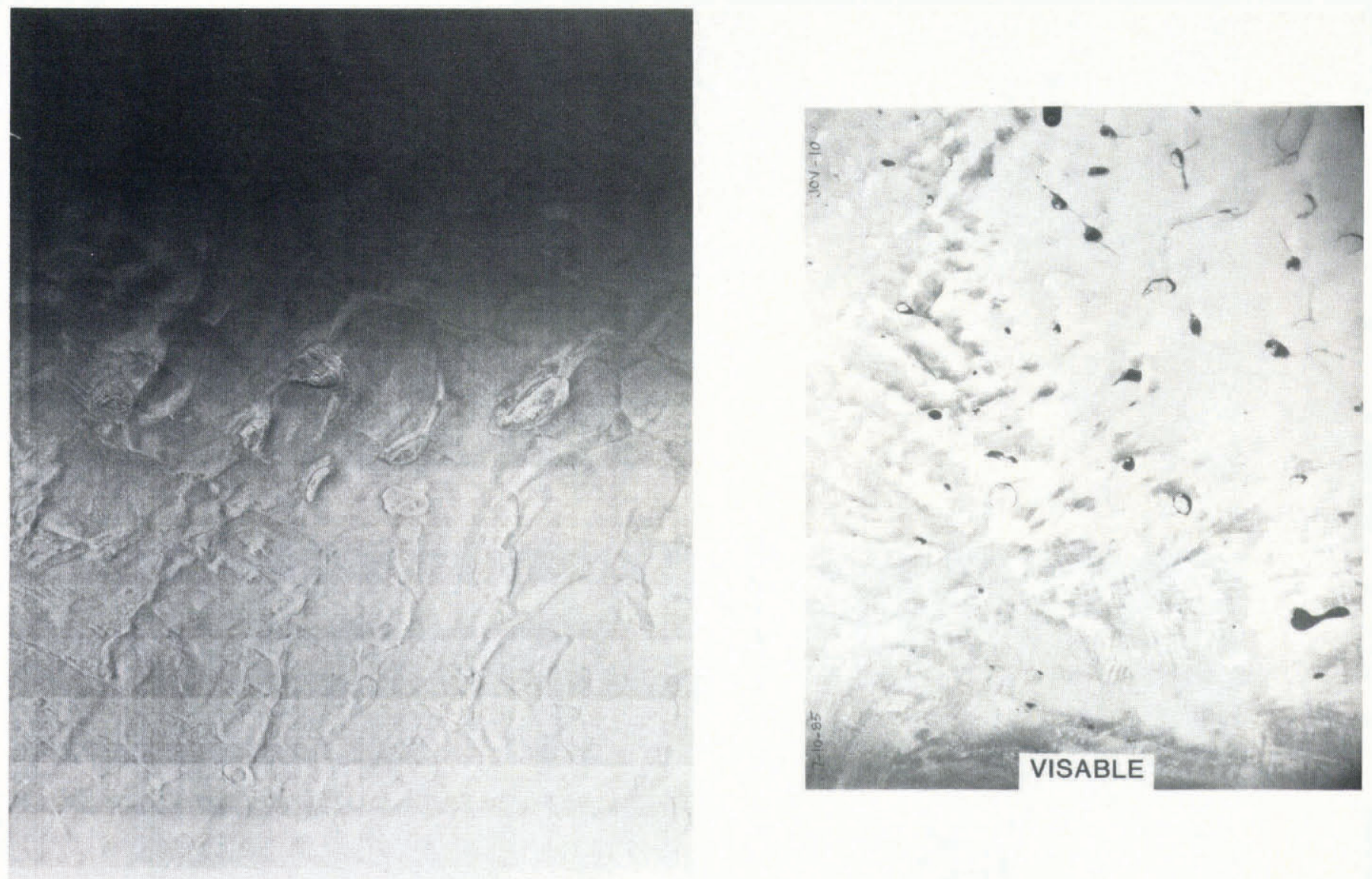

\section{SAR}

Fig.5. Comparison of part of Fig.4 with aerial photograph of surface lakes up-stream of Jakobshavns glacier, Greenland, taken on 10 July 1985. Scale of each image is approximately equal; height of SAR image is $45 \mathrm{~km}$. (Photograph is presented by courtesy of $\mathrm{H}$. Brecher.)

addition to sensing inactive and old lakes, the SAR appears to be detecting a branched drainage network through the winter snow cover.

In Fig. 4 it can be seen that the maximum contrast occurs in a band about two-thirds up from the bottom of the image. It is in this band that the system of lakes and branched drainage network is most easily seen, probably due to the SAR's sensitivity to surface slope. The rapid degradation of contrast on either side of this region illustrates the sensitivity of SAR to incidence angle.

As the flight proceeded eastward, much of the contrast was lost due to changes in instrument settings. There was a tonal variation which continued to trend in the north-east direction. Surface measurements of ice-sheet elevation confirm this trend up to the central ice divide (Drew and Whillans 1984) and surface radar-sounding data strongly suggest that the topographic trends are associated with basal relief (Whillans and others in press). East of the ice divide (not shown), there is a weak indication from the SAR data that the structural trend shifts to the east-south-east, in agreement with the coastal geology (Watterson 1978).

\section{COMPARISON OF AIRBORNE AND SEASAT SAR}

The eastern end of the airborne data overlapped the Seasat SAR data of eastern Greenland (see Fig.1). Thus, the same area was imaged by the two instruments. Fig.6 presents the two images at the same scale. Contrary to the situation on the western margin, the ice rapidly descends from the divide to the coast without any evidence of a zone of surface lakes. There is a general agreement in the two images but a number of significant differences are also revealed. While some of the differences can be understood in terms of the difference in instrument parameters, some may result from differences in the surface at the time of each image. This ambiguity highlights the need for simultaneous multi-frequency imaging; plans for such missions already exist.

The shadowing caused by the mountains is more extreme in the airborne data. This is due to the difference in antenna-depression angles for the two systems; the airborne data were taken with an antenna-depression angle of only $14^{\circ}$ while the Seasat data had a much higher depression angle of $67^{\circ}$. Thus, the surface incidence angle was much closer to grazing for the airborne data. The higher resolution of the airborne data allowed the identification of crevasse fields which only appeared as bright patches on the Seasat image.

A consistent pattern of tonal variability is present in the left-hand side of both images but, again, the airborne data have a better resolution. It is difficult to assess the consistency of the broader-scale variation because the airborne data in particular suffer from both an increase in darkening from bottom to top across the swath and occasional changes in instrument settings which cause the bulk changes in contrast along the swath. Nevertheless, there appear to be some differences in tonal pattern between the two images which might be due to differences in the surface at the two times of the images. These include the darker areas on the Seasat image which occur at the lower elevations where the glaciers are discharging into the fiords and the upper right corner where the brighter airborne SAR return would indicate sea ice and icebergs which do not appear on the Seasat image. The darker Seasat region might well have the same explanation as in Fig.2: a smooth, bare-ice surface, possibly wet, and, therefore, either a specular or highly attenuating reflector. In April, when the 


\section{AIRBORNE SAR}
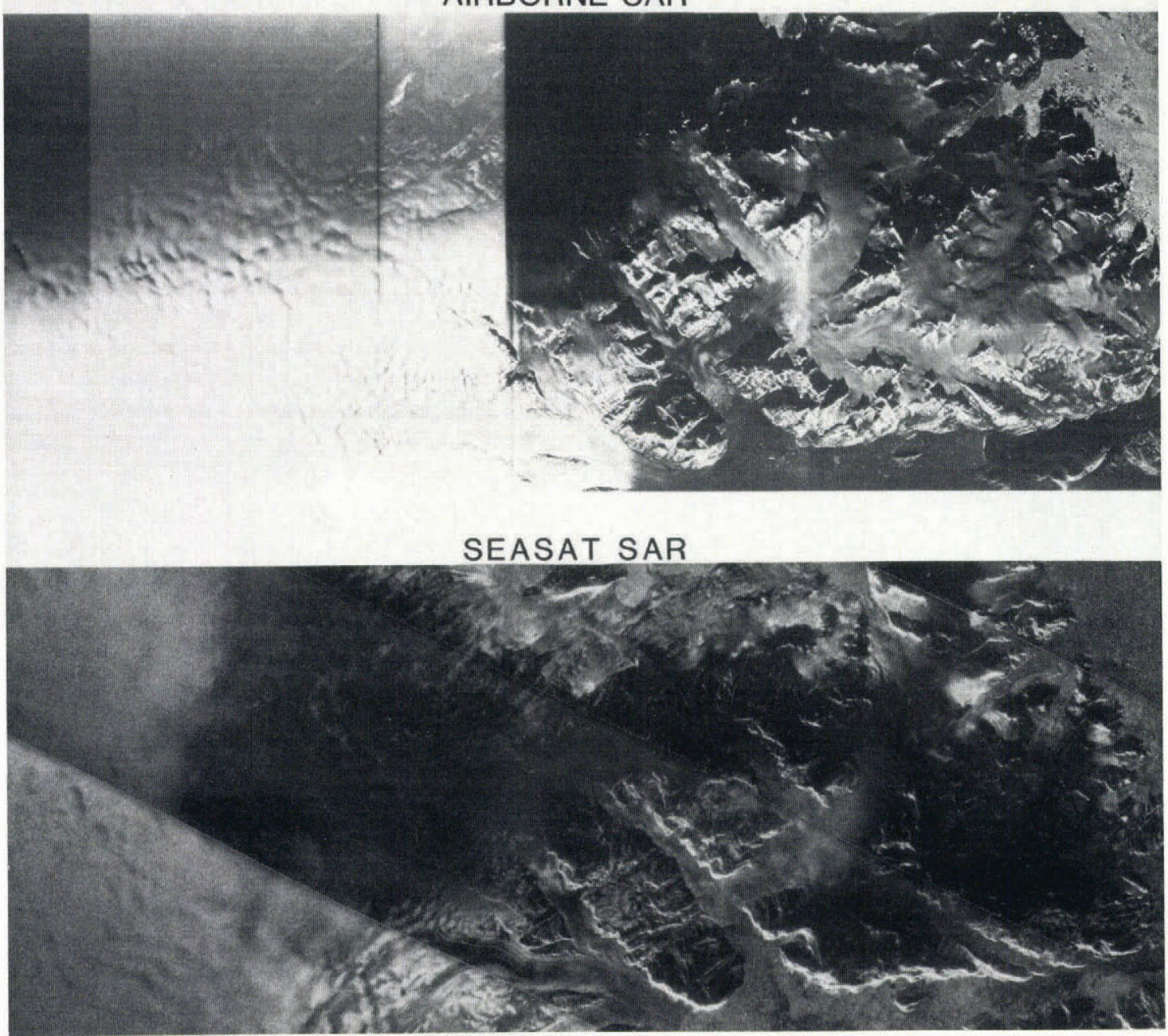

Fig.6. Comparison of eastern Greenland imaged with airborne X-band SAR (14 April 1986) with $15^{\circ}$ antenna depression angle and Seasat SAR (23 September 1978) with $70^{\circ}$ antenna depression angle. In airborne image, instrument settings were changed numerous times across the image. In both cases, illumination is from the bottom of the figure. Width of each swath is $45 \mathrm{~km}$.

airborne data were collected, it is likely that even the lower elevations are still covered with a blanket of snow and little melting, if any, has occurred. Similarly, icebergs and sea ice would be expected during April and not in September. Again, to firm up the interpretation, there is a need for coincident images at multiple frequencies.

\section{COMPARISON OF SAR AND LANDSAT IMAGES}

Hall and Ormsby (1983) have made a comparison of coincident SAR and Landsat MSS images for a few areas including the Malaspina glacier and Mount McKinley areas in Alaska. Their conclusion was that the SAR image contained no additional information which was not in the Landsat scene. Rott (1982) disagreed and demonstrated for Skeidarárjökull, Iceland, that Seasat SAR shows more detail than Landsat. Our position is that, because radar reflectivity varies much more strongly with the physical state of the ice or snow surface than does the optical reflectivity, SAR has a prominent role to play in glaciological research. Available comparisons between these two imagers show there can be information detected by either sensor which escapes the other. Consequently, it is most appropriate to view the two instruments as complementary rather than duplicative.

Another comparison was presented for the glaciers in the Karakoram of Pakistan using SIR-A and Landsat images (Ford and others 1983 , p. 112-13). That comparison showed that, while the medial moraines exposed on the surface in the ablation (bare-ice) zone could be seen on both images, these moraines could be traced far up-stream into the accumulation area on the SAR image but not on the
Landsat image. This difference is probably due to the penetration capability of the SAR.

Ford and others (1980, p. 100-01) presented a comparison between Seasat SAR and Landsat in western Greenland but they did not discuss the glaciological significance of the features. Fig.7 repeats these two images for our discussion. Fig.7a is a part of the image already shown in Fig.2. The SAR image was collected by Seasat on 9 October 1978, while the Landsat scene (ID\# 1448-14124) is from 14 October 1973. Many of the same features can be identified on both images even though the Landsat image has a much poorer resolution $(80 \mathrm{~m}$ as compared with $25 \mathrm{~m}$ ). Distortion of the SAR image prevents a direct overlaying of images without the aid of a sophisticated image-analysis computer, but the features in the SAR image such as crevassed outlet glaciers, a dark ablation zone, and mottled firn zone can be matched with regions of distinctive texture on the Landsat scene. The Landsat scene also helps identify the nunataks in the southern part of the image which are not particularly different from some of the smaller-scale ice features on the ice in the SAR image. Flow lines are far more distinct in the SAR image, particularly further up-stream. The scale of the patchy appearance of the SAR image is consistent with the scale of surface undulations observed with Landsat. One edge of the large V-shaped area in the SAR image shows up in the Landsat image as a ridge in the ice. Neither lakes nor streams are evident in the Landsat scene but show up dramatically with SAR.

A few other Landsat images were available for comparison with this West Greenland scene. Most were 


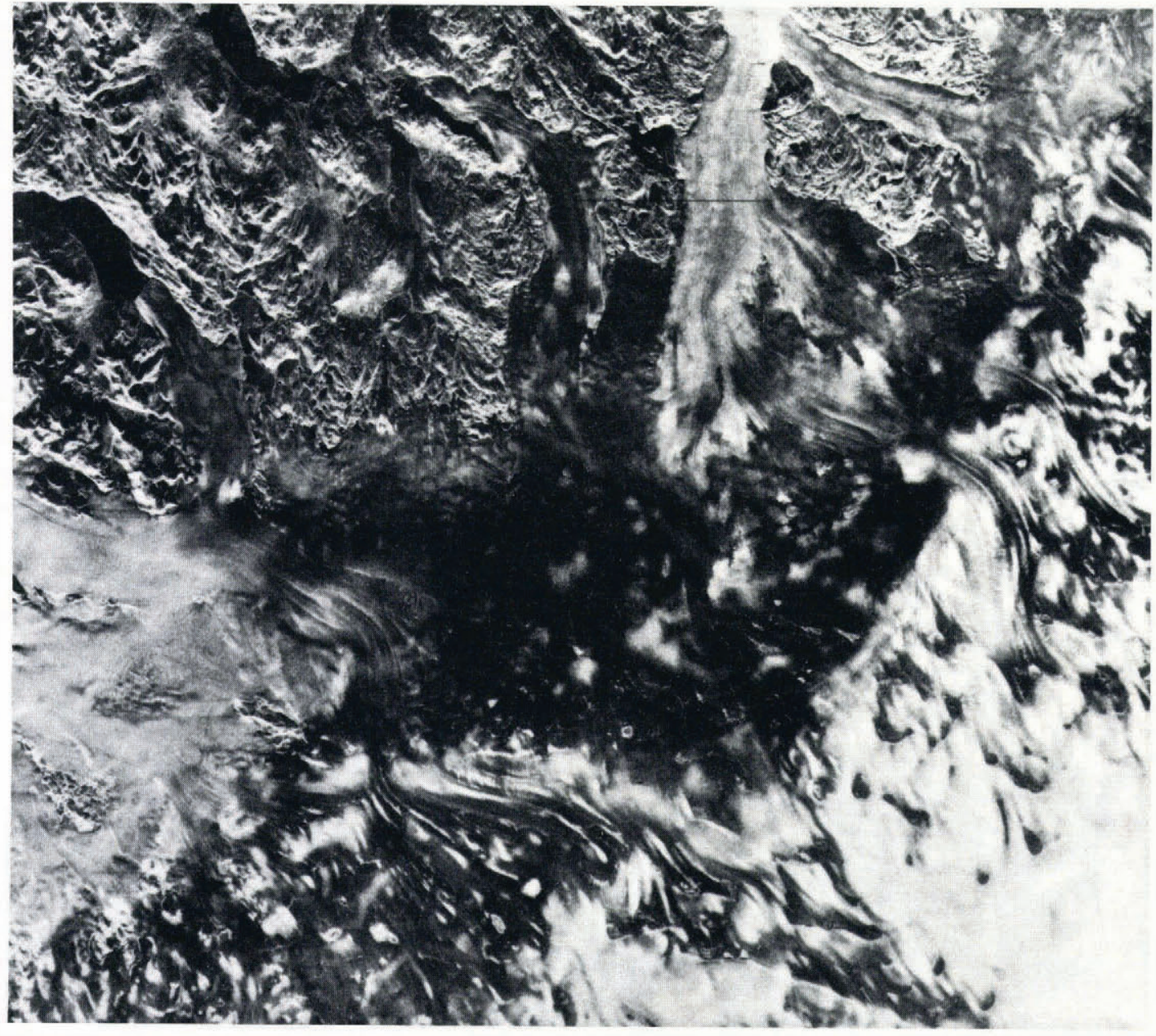

Fig.7a. Comparison of western Greenland images with Seasat SAR on 9 October 1978. Illumination is from the bottom of the image. Shape of Landsat scene is skewed to match SAR scene which has some distortion due to effects of surface relief.

cloud-covered but two are worth discussing: one taken in mid-winter (25 February 1981) and another taken on 27 September 1978, just 2 weeks before the SAR image. In the case of the mid-winter image, the low sun angle highlighted the surface topography slightly better than Fig.7b but, because the entire surface was snow-covered, it is difficult to see the margin of the ice sheet and impossible to see any difference between the firn and ablation areas. The image taken 2 weeks before the SAR image is important because it shows evidence of a fresh snowfall. This masked all but the most prominent surface features and rendered the image of little use. It also demonstrated that the SAR data were most likely collected over a surface covered with fresh snow, a situation which did not prevent the acquisition of valuable data (as was the case with Landsat).

We see the two sensors as highly complementary, their strengths meshing nicely. Landsat images contain minimal distortion because the instrument is nadir-pointing. Its multi-spectral characteristic has enabled enhanced images to highlight many important glaciologically significant features (Williams and Carter 1976; Swithinbank and Lucchitta 1986). These images can reveal subtle surface features when Sun elevations are low. SAR is sensitive to changes in the complex dielectric properties of the surface, surface roughness, and regional slope. Because the complex dielectric contrast between saturated snow and ice is greater than an order of magnitude, and because surface slopes on the interior of the ice sheet are small, much of the detail in SAR imagery is probably associated with variations in the surface composition. The all-weather capability of the SAR, as well as the fact that illumination angle and, to a lesser extent, radar frequency are operator-controlled, cannot be over-emphasized. We feel it is this characteristic, in particular, which will free the polar glaciologist from the frustrations of relying exclusively on visible imagery to study the polar ice sheets on a large scale.

\section{SUMMARY}

We have shown, by examples and comparisons, the power of SAR data in providing the glaciologist with a valuable source of data in image format. However, glaciological data are limited primarily because the SAR instruments developed so far have been designed exclusively for the oceanographic and the geologic communities. We think there is a need for the glaciological community to explore, in detail, the potential of SAR and the new instrument capabilities, such as multi-frequency and multipolarization, presently being planned. To do this, complementary surface and laboratory measurements of the electrical properties of snow and firn are called for, particularly to determine the depth of penetration of SAR signals and to correlate precisely tonal variations in the SAR image with surface properties. In the coming years there 


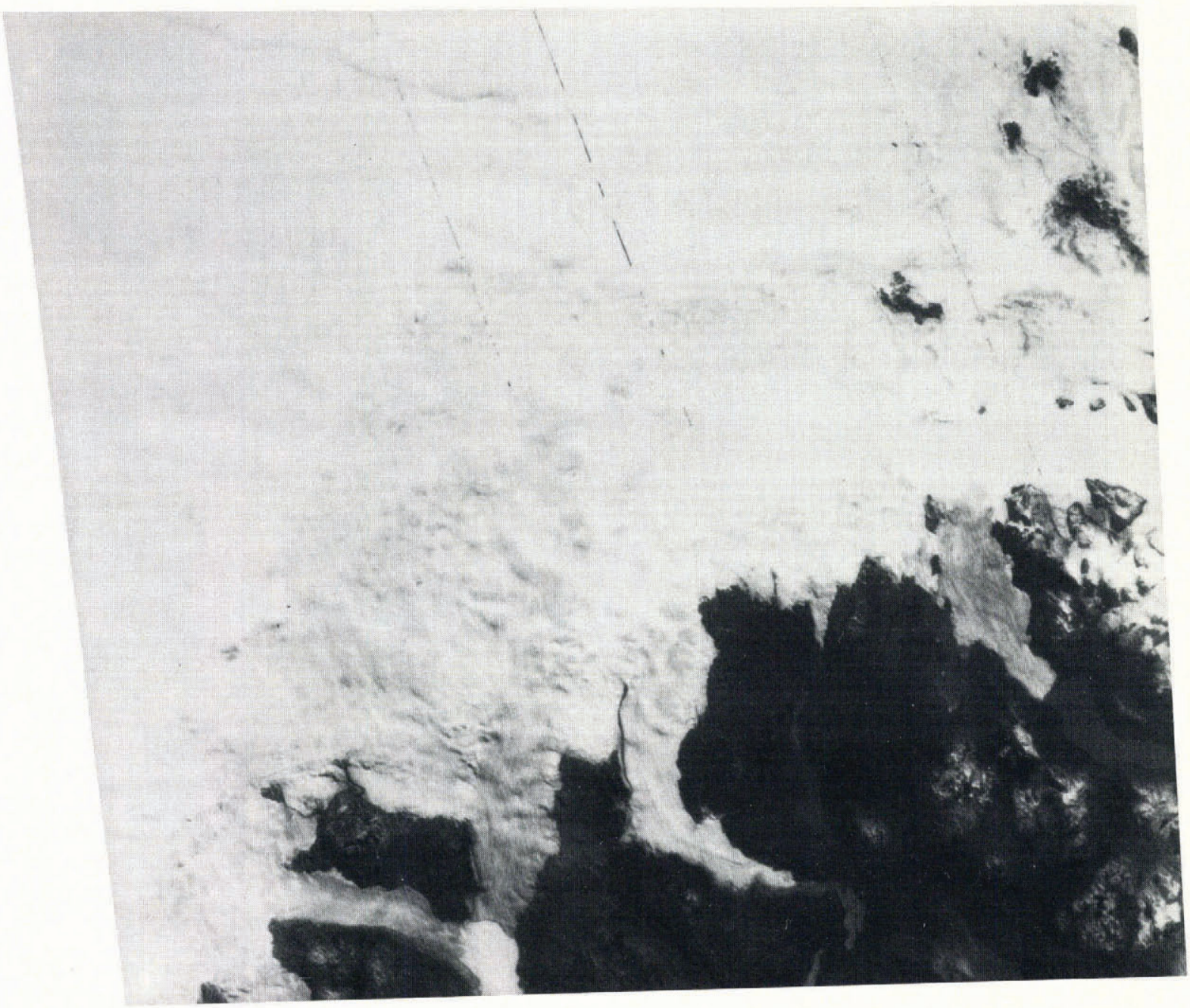

Fig.7b. Comparison of western Greenland imaged with unenhanced Landsat-1 (ID\# 1448-14124), on 14 October 1973.

will be numerous SAR instruments flown in space providing opportunities to collect unique data for mapping and benchmark purposes. With these data, the glaciologist can begin to study the polar ice sheets as complete units and monitor their effect on, and response to, global climate.

\section{REFERENCES}

Drew A R, Whillans I M 1984 Measurement of surface deformation of the Greenland ice sheet by satellite tracking. Annals of Glaciology 5: 51-55

Ford J P and 6 others 1980 Seasat views North America. the Caribbean, and western Europe with imaging radar. Pasadena, CA, Jet Propulsion Laboratory (Publication 80-67)

Ford J P, Cimino J B, Elachi C 1983 Space shuttle Columbia views the world with imaging radar: the SIR-A Experiment. Pasadena, CA, Jet Propulsion Laboratory (Publication 82-95)

Fu L L, Holt B 1982 Seasat views oceans and sea ice with synthetic aperture radar. Pasadena, CA, Jet Propulsion Laboratory (Publication 81-120)

Hall D K, Ormsby J P 1983 Use of Seasat synthetic aperture radar and LANDSAT multispectral scanner subsystem data for Alaskan glaciology studies. Journal of Geophysical Research 88(C3): 1597-1607

Jezek K C, Roeloffs E A, Greischar L L 1985 A geophysical survey of subglacial geology around the deep-drilling site at Dye-3 Greenland. In Langway C C $\mathrm{Jr}$, Oeschger $\mathrm{H}$, Dansgaard W (eds) Greenland ice core: geophysics. geochemistry and the environment. Washington, DC, American Geophysical Union: 105-110 (Geophysical Monograph 33)

Nichols A D, Wilhelm J W, Gaffield T W, Inkster D R, Leung S K 1986 A SAR for real-time ice reconnaissance. IEEE Transactions on Geoscience and Remote Sensing (GE 24(3): 383-389)

Rott H 1982 Synthetic aperture radar capabilities for glacier monitoring demonstrated with Seasat SAR data. Zeitschrift für Gletscherkunde und Glazialgeologie 16(2), 1980: 255-266

Rott H, Domik G 1984 The SAR-580 Experiment on snow and glaciers at the Austrian test site. In Trevett $\mathrm{J}$ W (ed) Proceedings of the SAR-580 Investigators Workshop. Joint Research Centre, Ispra, Italy May 1984. Paris, European Space Agency

Rott H, Domik G, Mätzler C, Miller H, Lenhart K G 1985 Study on use and characteristics of SAR for land snow and ice applications. Innsbruck, Universität Innsbruck. Institut für Meteorologie und Geophysik (Mitteilung 1)

Smith B M E, Evans S 1972 Radio echo sounding: absorption and scattering by water inclusion and ice lenses. Journal of Glaciology 11(61): 133-146

Stiles W H, Ulaby F T 1982 Dielectric properties of snow. CRREL Special Report 82-18: 91-103

Swithinbank C, Lucchitta B K 1986 Multispectral digital image mapping of Antarctic ice features. Annals of Glaciology 8: 159-163 
Thomas R H and 8 others 1985 Satellite remote sensing for ice sheet research. Washington, DC, National Aeronautics and Space Administration (Technical Memorandum 86233)

Ulaby F T, Moore R K, Fung A K 1982 Microwave remote sensing active and passive. Vol 2. Radar remote sensing and surface scattering and emission theory. Reading, MA, Addison-Wesley

Watterson J 1978 Proterozoic intraplate deformation in the light of south-east Asian neotectonics. Nature 273(5664): 636-640

Whillans I M, Jezek K C, Drew A R, Gundestrup N 1984 Ice flow leading to the deep core hole at Dye 3, Greenland. Annals of Glaciology 5: 185-190

Whillans I $\mathrm{M}$ and 6 others In press Glaciologic transect in southern Greenland; 1980-1981. GISP I data. Byrd Polar Research Center. Report

Williams R S Jr, Carter W D (eds) 1976 ERTS-1: a new window on our planet. US Geological Survey. Professional Paper 929 